\title{
Metastatic Liposarcoma
}

National Cancer Institute

\section{Source}

National Cancer Institute. Metastatic Liposarcoma. NCI Thesaurus. Code C8816.

A liposarcoma that has metastasized to a secondary site. 